\title{
Day-to-Day Energy Expenditure Variability in Low Birth Weight Neonates
}

\author{
KEITH H. MARKS, ELIZABETH E. NARDIS, AND JANICE A. DERR \\ Division of Newborn Medicine, Department of Pediatrics, The Milton S. Hershey Medical Center, The \\ Pennsylvania State University, College of Medicine, Hershey, Pennsylvania 17033 and Department of Statistics, \\ The Pennsylvania State University, University Park, Pennsylvania 16802 [J.A.D.]
}

\begin{abstract}
We estimated the metabolic rate of 13 low birth weight infants over a 9-day period, using indirect calorimetry in conjunction with serial measurements of oxygen consumption, carbon dioxide production, and total urinary nitrogen excretion. The mean percent error for oxygen consumption and carbon dioxide production measurements (determined by alcohol combustion experiments) assignable to the open-circuit system was 0.4 and $3.8 \%$, respectively. Error in the total urinary nitrogen excretion measurement was $<1 \%$ by the Kjeldahl technique. In the clinical setting, however, the range of deviation of measured oxygen consumption, carbon dioxide production and total urinary nitrogen excretion was $\pm 12,12$, and $15 \%$ of the mean value respectively for an individual patient under standardized controlled conditions. The variability of metabolic rate between infants may be as much as $76 \%$. Factors that had a small effect on metabolic rate were difficult to detect because of the variability inherent in the short-term measurement of metabolic rate. It was virtually impossible to control the sources of variation in the resting metabolism of low birth weight neonates over extended experimental periods. Day-to-day variations in resting energy expenditure may explain, in part, the widely different growth rates of premature infants receiving similar caloric intakes. (Pediatr Res 21: 66-71, 1987)
\end{abstract}

\section{Abbreviations}

$\dot{M} R$, metabolic rate

$\dot{\mathrm{V}} \mathrm{O}_{2}$, oxygen consumption

$\dot{\mathrm{V}} \mathrm{CO}_{2}$, carbon dioxide production

TUN, total urinary nitrogen excretion

NPRQ, nonprotein respiratory quotient

EOG, electrooculogram

There has been an increased interest in the sources of variation in energy expenditure that occur among very low birth weight infants in the modern clinical setting (1-6). Recently, Schulze et al. (7-9) made an assessment of minute ventilation, heart rate, and gaseous metabolism in relation to the state of activity and feeding cycle of growing low birthweight infants. They showed that the infants were prone to significant (4.7 to $24.6 \%$ ) swings in energy expenditure even under (apparently) strict basal con-

Received October 7. 1985: accepted August 25, 1986.

Address correspondence and reprint requests to Dr. Keith H. Marks, Department of Pediatrics. The Milton S. Hershey Medical Center. The Pennsylvania State University, P.O. Box 850. Hershey. PA 17033.

Supported by a grant from the Whitaker Foundation, 3M Company and the National Institute of Child Health and Human Development (HD-16399). ditions, and concluded that steady state conditions do not occur in growing low birth weight infants.Abdulrazzaq and Brooke (10) measured respiratory metabolism of premature infants and discussed body weight, activity, and energy intake in relation to 24 $\mathrm{h}$ measurements of energy expenditure. These authors found that $\dot{\mathrm{VO}}_{2}$ measured over a 3 -h period might lie anywhere between $13.8 \%$ above to $12.6 \%$ below the value obtained from the 24-h mean $\mathrm{VO}_{2}$. In contrast, Rutter et al. (11) and Gudinchet et al. (12) found only small variations (3-6\%) in repeated measurements of resting $\dot{\mathrm{VO}}_{2}$ within infants over a 24-h period. Similarly, Catzeflis et al. (13) found a stable pattern of energy expenditure in very low birth weight infants fed at constant intermittent intervals and extrapolated single 90 -min to 3 -h measurements of energy expenditure to $24 \mathrm{~h}$.

Interest in the mechanisms responsible for these conflicting results led us to make longitudinal replicate measurements of $\dot{\mathrm{V}} \mathrm{O}_{2}, \dot{\mathrm{V}} \mathrm{CO}_{2}$, and total urinary nitrogen to determine with indirect calorimetry the average day-to-day variability of metabolic rate within and between low birth weight infants under controlled conditions.

\section{PATIENTS AND METHODS}

The 13 very low birth weight infants were without major medical problems, were tolerating feeds and gaining weight. Informed parental consent was obtained for each child. Data regarding weight, age, nutritional intake, and complications before measurements are provided in Table 1. Body weight was determined daily on a beam balance accurate to $10 \mathrm{~g}$. Each baby received ready-to-feed formula at three hourly intervals by orogastric or nasogastric lavage. We weighed the containers before and after feeding to calculate caloric intake from the declared energy value of the formula. The dietary intake provided approximately $2 \frac{1}{2}$ times maintenance energy requirements (3) and remained constant (per $\mathrm{kg}$ body weight) throughout the 9-day study period. All patients received $1 \mathrm{ml}$ Polyvisol (Mead Johnson, Evansville, IN) daily. Patient 11 was treated with caffeine citrate $\left(5 \mathrm{mg} \mathrm{kg}{ }^{-1}\right.$ po) daily for apnea and patient 13 received 1 tsp of rice cereal $\left(3.75 \mathrm{kcal} \mathrm{g}^{-1}\right)$ with feeds to prevent gastroesophageal reflux.

Having been admitted into the study, each infant was scheduled to complete six sequential measurements of $\dot{\mathrm{VO}}_{2}$ and $\dot{\mathrm{V}} \mathrm{CO}_{2}$ to determine the range of resting energy expenditure over a period of 9 consecutive days. The study protocol used to measure metabolic rate required the infant's body temperature to be stable in conditions approximating the neutral thermal environment with the infant lying supine for $2 \mathrm{~h}$. Measurements started $1 \mathrm{~h}$ after a feed and at the same time each afternoon. Heart rate, respiration rate, and activity level were continuously monitored. Included in the metabolic rate measurements were periods of deep sleep, light sleep [determined by standard behavioral and physiologic criteria (14)], and quiet wakefulness with a minimum of gross body movements (but exclusive of crying). 
ENERGY EXPENDITURE VARIABILITY IN NEONATES

Table 1. Clinical and nutritional characteristics of 13 low birthwt infants

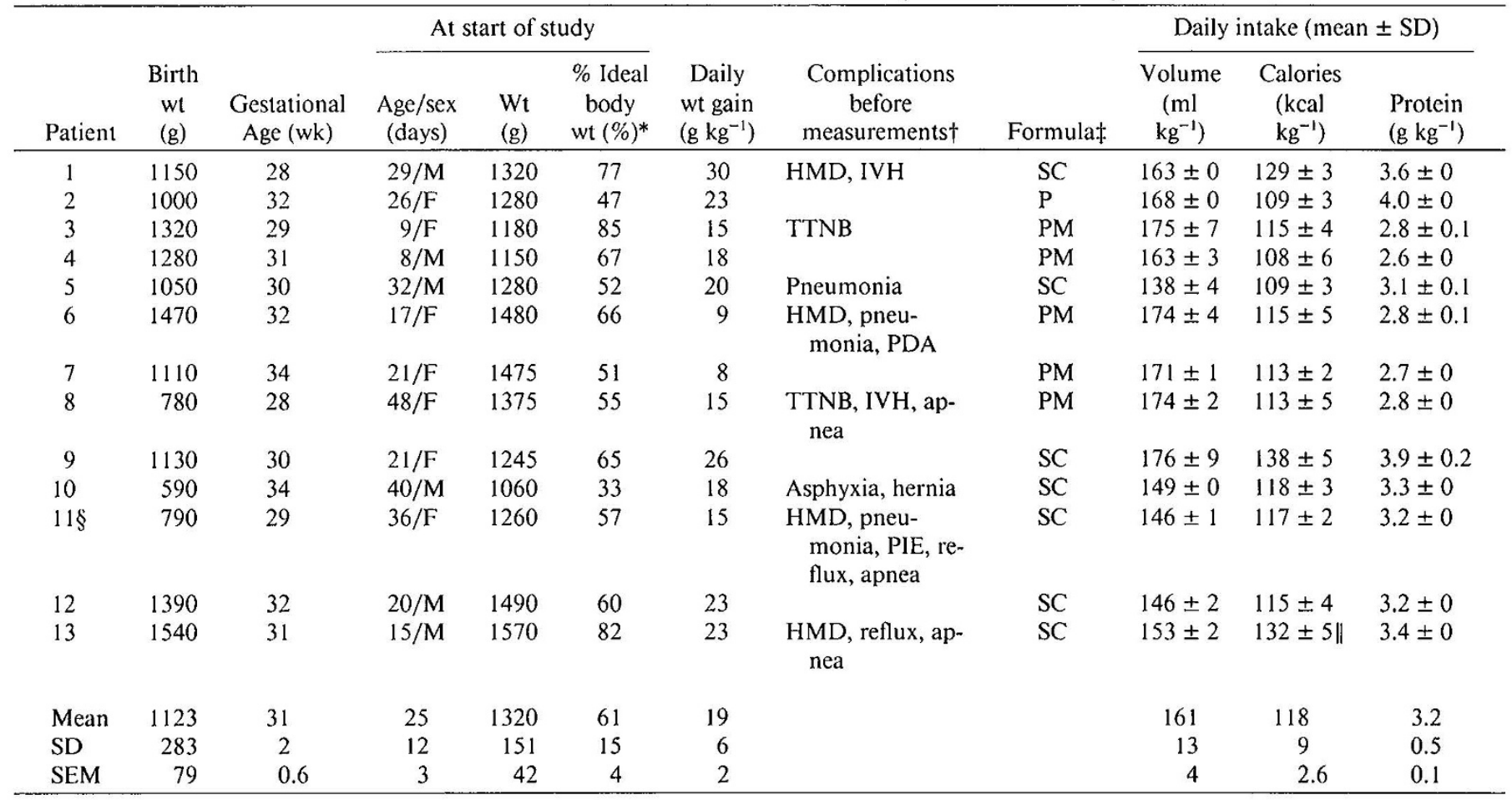

* Wt expressed as a percent of a normal infant of the same age, using the 50th percentile of the Lubchenco standard (37).

$\dagger$ Abbreviations used: HMD, hyaline membrane disease; IVH, intraventricular hemorrhage, TTNB, transient tachypnea of the newborn; PDA, patent ductus arteriosus; PIE, pulmonary interstitial emphysema.

† SC, Special Care; PM, PM 60/40 (Ross Laboratories); P, Portagen (Mead Johnson). Manufacturer’s Stated Values: Special Care, 81 kcal dl-1; Portagen, $67 \mathrm{kcal} \mathrm{dl}^{-1}$; PM 60/40, $67 \mathrm{kcal} \mathrm{dl}^{-1}$.

$\S$ Patient 11 received caffeine citrate $\left(5 \mathrm{mg} \mathrm{kg}^{-1} \mathrm{po}\right)$ daily throughout the study.

॥ Patient 13 also received 1 tsp rice cereal $\left(3.8 \mathrm{kcal} \mathrm{g}^{-1}\right)$ with each feed.

Oxygen consumption and carbon dioxide production were determined with an open-circuit technique described in detail in the companion paper (15). Respiratory gas exchange was analyzed every $100 \mathrm{~s}$ from a continuous recording of the output from the paramagnetic $\mathrm{O}_{2}$ and IR $\mathrm{CO}_{2}$ gas analyzers, and $\mathrm{VO}_{2}$ and $\dot{\mathrm{VCO}}_{2}$ subsequently calculated as mean values for each observation period. During the study, three $24-\mathrm{h}$ urine samples per infant were collected and analyzed (in duplicate) for total nitrogen by the micro-Kjeldahl method (16). Gaseous metabolism and urine collection periods were contiguous. $\dot{M R}$ and the NPRQ were calculated according to standard assumptions of indirect calorimetry using Jéquier's formula (17).

\section{DATA ANALYSIS}

The values for $\dot{\mathrm{VO}} \mathrm{O}_{2}, \dot{\mathrm{V}} \mathrm{CO}_{2}$, and TUN used to predict $\dot{\mathrm{M}} \mathrm{R}$ incorporate a correction for the overall methodological and instrumentation error calculated as follows. $\dot{\mathrm{VO}} 2, \dot{\mathrm{V}} \mathrm{CO}_{2}$, and TUN measurements were made over the range encountered in the clinical studies using absolute alcohol combustion (15) and stock urea solutions (16) respectively, as laboratory standards. The relation between the measured values and the true values made under ideal conditions was estimated by linear regression. The fitted line and its $95 \%$ confidence band was plotted using a high resolution graphics procedure (SAS GRAPH, Statistical Analysis System software package, version OS 82.3, SAS Institute, Inc., Cary, NC) (Fig. 1). The equation for the fitted line was in the general form $Y=\beta_{0}+\beta_{1} X$. Where: $Y=$ measured value (dependent variable); $\mathrm{X}=$ true value (independent variable); $\beta_{1}$ $=$ slope of the fitted line; $\beta_{0}=$ intercept of line on vertical axis.

For each infant, the mean values and $95 \%$ confidence intervals of $\dot{\mathrm{VO}_{2}}, \dot{\mathrm{V} C O}$, and TUN measurements were calculated from the following equation (18):

$$
\bar{Y} \pm t{ }_{d f}^{\alpha / 2} \sqrt{\frac{M S E}{n}}
$$

where: $\overline{\mathrm{Y}}=$ mean value of $\dot{\mathrm{VO}}_{2}, \dot{\mathrm{V}} \mathrm{CO}_{2}$, TUN from $(\mathrm{n})$ measurements per infant; $n=$ number of measurements per infant; MSE $=$ mean square error (this is a measure of the average within subject variation); $\mathrm{df}=$ degrees of freedom used to determine $\mathrm{t}$; $\mathrm{t}=\mathrm{t}$ statistic with the degree of "confidence" that is associated with the resulting interval. We chose $\alpha=0.05$ (two-tailed).

Figure 1 shows how the best estimate of the true mean value $(\overline{\mathrm{X}})$ of $\dot{\mathrm{V}} \mathrm{O}_{2}, \dot{\mathrm{V} C O}{ }_{2}$, and TUN was determined from the measured value $(\overline{\mathrm{Y}})$. The $90 \%$ confidence interval of $\dot{\mathrm{VO}}_{2}, \dot{\mathrm{V} C O}$, and TUN for each infant was determined by the projection of the $95 \%$ confidence interval of $\bar{Y}$ through the $95 \%$ confidence band of the regression line to the $\mathrm{X}$ axis (Fig. 1) (18). The $95 \%$ confidence intervals of NPRQ and $\dot{M R}$ were obtained from large sample approximations (19).

\section{RESULTS}

As shown in Table 1 , the 13 patients who met the selection criteria represent a heterogenous population of low birth weight infants whose ages ranged from 8 to 48 days (eight were female and five male). All but two patients had surpassed their birth weight; but both of these (patients 3 and 4) had established weight gain. There was a previous history of undernutrition (mean \% ideal body weight $=61 \%$, range $33-85 \%$ ) in all patients coincident with their extreme prematurity or serious illness in the first weeks of life. All infants gained weight during the study although the rate of daily weight gain was very variable from one 


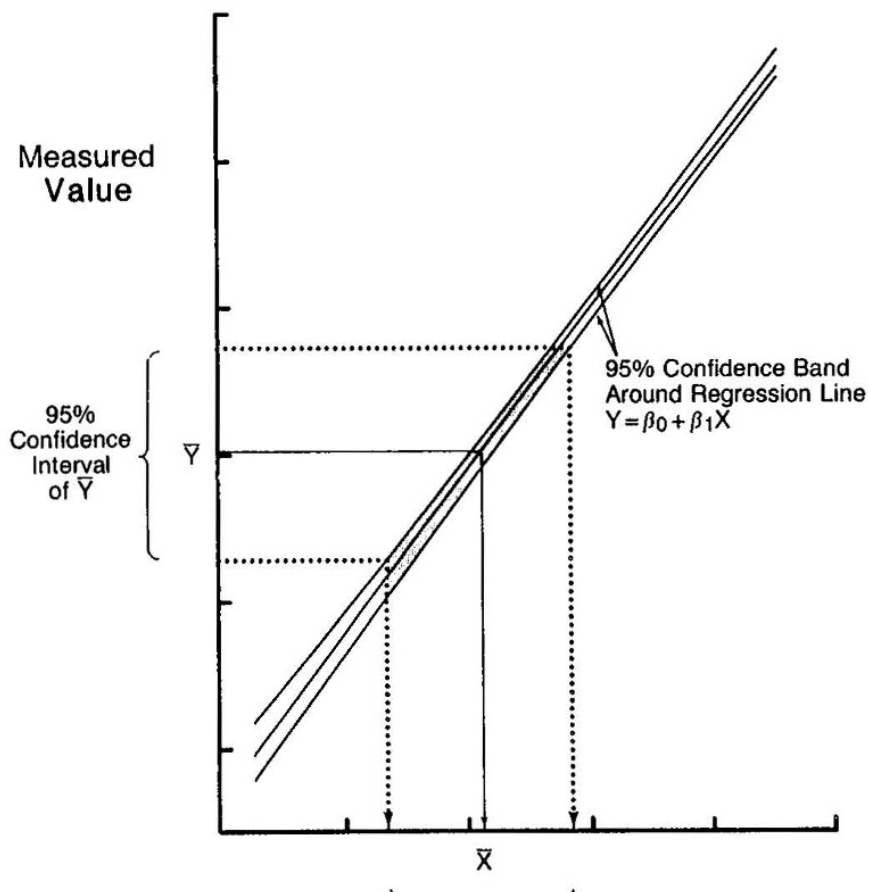

$90 \%$ Confidence Interval of $\bar{X}$ mean of six 2-h observation periods (range 40-173 min), whereas values for TUN are the mean of three 24-h urine collection periods (range 18-24 h). The daily total urinary nitrogen loss for individual infants ranged from 53 to $112 \mathrm{mg} \mathrm{kg}^{-1}$ (mean $\pm \mathrm{SEM}$, $70 \pm 5 \mathrm{mg} \mathrm{kg}^{-1}$ ). This was slightly lower than the mean value for TUN reported in the literature $(25)$ but yet within the normal range particularly when the type of formula used and the infant's prior intake of protein was taken into account $(26,27)$. Expressed in terms of protein utilization, the total urinary nitrogen excreted was between 9 and $23 \%$ (mean \pm SEM, $14 \pm 1 \%$ ) of the daily protein intake of $\sim 3.2 \mathrm{~g} \mathrm{~kg}^{-1}$ (protein $=$ nitrogen $\times 6.25$ ). The volume of urine collected during the measurement period was $80 \pm 4 \mathrm{ml} \mathrm{kg}^{-1}$ (mean \pm SEM).

Also presented in Table 2 are the $90 \%$ confidence intervals around the best estimate of the true mean values for $\dot{\mathrm{VO}}_{2}, \dot{\mathrm{V}} \mathrm{CO}_{2}$, and TUN excretion. By minimizing the variation due to methodological and instrumentational errors, together with standardizing the test conditions as precisely as possible, the within-infant variability presented in Table 2 can be considered to be those due mainly to biological day-to-day variations in expenditure. The MR varied considerably from patient to patient, ranging from 1.86 to $3.27 \mathrm{kcal} \mathrm{kg}^{-1} \mathrm{~h}^{-1}$, reflecting considerable physiological differences between infants. Of interest are the data from patient 11 with apnea spells who received caffeine citrate daily ( $5 \mathrm{mg} \mathrm{kg}^{-1}$ po), a methylxanthine and $\beta$-adrenergic stimulant known to effect the metabolic rate in the direction we observed.

\section{DISCUSSION}

Fig. 1. Use of the regression graph with confidence bands to compute the best estimate of the true mean value $(\bar{X})$ and its $90 \%$ confidence interval for $\dot{\mathrm{V}} \mathrm{O}_{2}, \dot{\mathrm{V} C O}{ }_{2}$, and TUN. The regression line $\left(\mathrm{Y}=\beta_{0}+\beta_{1} \mathrm{X}\right)$ and its $95 \%$ confidence bands was estimated from measured values related to true values using laboratory standards $(15,16) . \bar{Y}$ represents the mean value of $(n)$ measurements per infant. The dotted lines show the $95 \%$ confidence interval of $\bar{Y}$ and their intersection with the $95 \%$ confidence bands of the regression line. Projection to the $\mathrm{X}$ axis determines the $90 \%$ confidence interval around the best estimate of the true mean value $(\bar{X})(18)$.

infant to another (range $8-30 \mathrm{~g} \mathrm{~kg}^{-1}$ ). These findings were in accord with those from a larger study of catch-up growth in low birth weight infants recovering from their acute illness (20). The daily values for the volume, caloric, and protein intake of milk formula for each infant are also presented in Table 1. The average coefficient of variation of the daily energy intake throughout the study was $3 \%$ (range $1.7-5.6 \%$ ) and was accounted for by the mass of formula lost by vomitus, burps, or spillage. We assumed that the small variation in caloric intake during the study was of no consequence. All patients completed the study and there were no adverse clinical events.

The infants were usually asleep during measurements so that sleep accounted for $>90 \%$ of the total measurement time. The coefficient of variation (mean \pm SEM) during each 2-h measurement of gaseous metabolism within the same infant was $10 \pm$ $1.2 \%$ and $12 \pm 1.9 \%$ for $\dot{\mathrm{VO}}_{2}$ and $\dot{\mathrm{VCO}}_{2}$, respectively. This spontaneous variability of respiratory gas exchange within individual measurements may be attributed to the expected relationship between $\dot{\mathrm{VO}} 2, \dot{\mathrm{V}} \mathrm{CO}_{2}$, and state of activity (quiet sleep, active sleep, and quiet wakefulness) over the measurement period and was within the range of previous findings (21-24). Table 2 summarizes the results from the longitudinal measurements of $\dot{\mathrm{V}} \mathrm{O}_{2}, \dot{\mathrm{VCO}}_{2}$, and TUN excretion for each infant. Seventy-eight measurements, or six measurements per infant, of $\mathrm{VO}_{2}$ were made; $\mathrm{VCO}_{2}$ measurements from three infants were not obtained because of technical difficulties, so there was a total of $62 \dot{\mathrm{VCO}}_{2}$ measurements. The values for $\mathrm{VO}_{2}$ and $\mathrm{VCO}_{2}$ in Table 2 are the
Longitudinal measurements of energy expenditure made on each infant at regular intervals, in the same laboratory, and with constant methodology permits correction for the inevitable interindividual differences of $\dot{M} R$ related to weight, gestational age, postnatal age, growth rate, and nutritional intake (28). Our results of energy expenditure variability from serial determinations of $\dot{M R}$ on the same infant tend to agree with the previous observations (7-9) that measurements of gaseous metabolism in resting low birth weight infants, even under carefully controlled conditions, was considerable. Our analysis showed variations of some $10 \%$ within a measurement of $\mathrm{VO}_{2}$ lasting $2 \mathrm{~h}$, whereas $\mathrm{VO}_{2}$ measured on the same infant repeated on another day under as nearly as possible the same conditions may have been $12 \%$ Allowing for a minimum measurement error of $\pm 4 \%$ (29), we may conclude that the absolute biological day-to-day variation of $\mathrm{VO}_{2}$ within an infant under these conditions was over a range of $\pm 8 \%$ for a measurement lasting $2 \mathrm{~h}$. Alternatively, we could also reasonably conclude that the open-circuit indirect calorimetry technique is less reproducible in the clinical setting.

The results of the present investigation seem to contradict those obtained by Rutter et al. (11) who measured the resting rate of oxygen consumption of small babies over a period of 3 to $15 \mathrm{~min}$. They found only small variations in serial $\mathrm{VO}_{2}$ measurements repeated over $24 \mathrm{~h}$ and from day-to-day. The disparities observed were probably partially due to the differences between measurement periods. The longer the sampling interval, the more likely it was that multiple behavioral states, periods of wakefulness, or body movements were included in the sample. Such factors, if present, greatly increase the variability of the sample. In two previous studies using calorimetry systems designed for prolonged $(24 \mathrm{~h})$ continuous $\mathrm{VO}_{2}$ measurements, Abdulrazzq and Brooke (10) reported differences of about $13 \%$ between highest and lowest $\dot{\mathrm{VO}}_{2}$ measurements during a 24-h study period. They drew attention to the possibility of considerable error in assuming that short term measurements (5-15 min) were representative of minimal resting metabolism or of energy expenditure over prolonged periods. In contrast, Gudinchet $e t$ al. (12) reported a stable pattern of $\mathrm{V}_{2}$ over a 24 -h period on 2 below or $11 \%$ above the best estimate of the true mean value. 
Table 2. Indirect calorimetry data for 13 low birth wt infants; $\dot{V} \mathrm{O}_{2}, \dot{V} \mathrm{CO}_{2}$ measurd by open-circuit system (15) and TUN measured by micro-Kjeldahl method (16); NPRQ and $\dot{M R}$ derived by indirect calorimetry methods (17)

\begin{tabular}{|c|c|c|c|c|c|c|c|c|c|c|c|c|c|c|c|c|c|c|c|c|c|c|c|}
\hline \multirow[b]{3}{*}{ Patient } & \multicolumn{5}{|c|}{$\dot{\mathrm{VO}}_{2}\left(\mathrm{ml} \mathrm{kg}^{-1} \mathrm{~min}^{-1} \mathrm{STPD}\right)$} & \multicolumn{5}{|c|}{$\dot{\mathrm{V}} \mathrm{CO}_{2}\left(\mathrm{ml} \mathrm{kg}^{-1} \mathrm{~min}^{-1} \mathrm{STPD}\right)$} & \multicolumn{5}{|c|}{ TUN (mg kg $\left.{ }^{-1} \mathrm{~h}^{-1}\right)$} & \multicolumn{4}{|c|}{ NPRQ } & \multicolumn{4}{|c|}{$\dot{\mathrm{M} R}\left(\mathrm{kcal} \mathrm{kg}^{-1} \mathrm{~h}^{-1}\right)$} \\
\hline & \multirow[b]{2}{*}{$\bar{Y}(\mathrm{n}) \dagger$} & \multirow[b]{2}{*}{$\overline{\mathrm{X}} \ddagger$} & \multicolumn{2}{|c|}{$\begin{array}{l}90 \% \text { confidence } \\
\text { intervals }\end{array}$} & \multirow{2}{*}{$\begin{array}{l}\text { Band- } \\
\text { width\| } \\
(\%)\end{array}$} & \multirow[b]{2}{*}{$\bar{Y}(\mathrm{n}) \dagger$} & \multirow[b]{2}{*}{$\bar{X} \ddagger$} & \multicolumn{2}{|c|}{$\begin{array}{l}90 \% \text { confidence } \\
\text { intervals§ }\end{array}$} & \multirow{2}{*}{$\begin{array}{c}\text { Band- } \\
\text { width\| } \\
(\%)\end{array}$} & \multirow[b]{2}{*}{$\overline{\mathrm{Y}}(\mathrm{n}) \dagger$} & \multirow[b]{2}{*}{$\overline{\mathrm{X}} \dot{q}$} & \multicolumn{2}{|c|}{$\begin{array}{c}90 \% \\
\text { confidence } \\
\text { intervals§ }\end{array}$} & \multirow{2}{*}{$\begin{array}{l}\text { Band- } \\
\text {-width\| } \\
(\%)\end{array}$} & \multirow[b]{2}{*}{ Mean } & \multicolumn{2}{|c|}{$\begin{array}{l}95 \% \\
\text { confidence } \\
\text { limits }\end{array}$} & \multirow{2}{*}{$\begin{array}{c}\text { Band- } \\
\text {-width\| } \\
(\%)\end{array}$} & \multirow[b]{2}{*}{ MeanI } & \multicolumn{2}{|c|}{$\begin{array}{c}95 \% \\
\text { confidence } \\
\text { limits }\end{array}$} & \multirow{2}{*}{$\begin{array}{r}\text { Band- } \\
\text { - width } \\
\quad(\%) \\
\end{array}$} \\
\hline & & & Lower & Upper & & & & Lower & Upper & & & & Lower & Upper & & & Lower & Upper & & & Lower & Upper & \\
\hline 1 & $8.46(6)$ & 8.70 & 7.71 & 9 & 9.9 & $8.48(6)$ & 8.19 & 7.29 & 8.96 & 10.2 & $2.23(3)$ & 2.25 & 1.81 & 2.64 & 18.4 & 0.94 & .82 & 1.06 & 12.8 & 2.58 & 2.43 & 2.70 & 5.2 \\
\hline 2 & $7.69(6)$ & 8.05 & 7.10 & 8.91 & 11.2 & & & & & & $4.66(3)$ & 4.63 & 4.20 & 5.07 & 9.4 & & & & & & & & \\
\hline 3 & $7.75(6)$ & 8.18 & 7.06 & 9.25 & 13.4 & & & & & & $4.33(3)$ & 4.32 & 3.89 & 4.79 & 10.4 & & & & & & & & \\
\hline 4 & $7.69(6)$ & 8.16 & 7.00 & 9.22 & 13.6 & $8.63(6)$ & 8.37 & 7.24 & 9.47 & 13.3 & $3.27(3)$ & 3.24 & 2.80 & 3.70 & 13.9 & 1.03 & .89 & 1.16 & 13.1 & 2.47 & 2.29 & 2.65 & 7.3 \\
\hline 5 & $7.91(6)$ & 8.23 & 7.14 & 9.14 & 12.2 & $8.59(6)$ & 8.25 & 7.29 & 9.22 & 11.7 & $2.20(3)$ & 2.19 & 1.78 & 2.60 & 18.7 & 1.00 & .88 & 1.12 & 12.0 & 2.48 & 2.32 & 2.64 & 6.5 \\
\hline 6 & $7.30(6)$ & 7.59 & 6.66 & 8.44 & 11.7 & $7.46(6)$ & 7.22 & 6.39 & 8.04 & 11.4 & $2.89(3)$ & 2.88 & 2.50 & 3.30 & 13.9 & 0.95 & .84 & 1.06 & 11.6 & 2.25 & 2.11 & 2.39 & 6.3 \\
\hline 7 & $6.82(6)$ & 7.12 & 6.23 & 7.91 & 11.8 & $6.38(6)$ & 6.15 & 5.25 & 7.00 & 14.2 & $2.79(3)$ & 2.78 & 2.40 & 3.18 & 14.0 & 0.86 & .75 & 0.98 & 13.4 & 2.07 & 1.93 & 2.21 & 6.8 \\
\hline 8 & $8(6)$ & 8 & 8.08 & 9.79 & 9 & $8.43(6)$ & 8.07 & 7.20 & 8.95 & 10. & $2.38(3)$ & 2.38 & 1.96 & 2.80 & 17.6 & 0.90 & .81 & 1.00 & 10.6 & 2.63 & 2.48 & 2.77 & 5.6 \\
\hline 9 & $8.41(6)$ & 8.70 & 7.63 & 9.67 & 11.7 & $8.46(6)$ & 8.17 & 7.48 & 9.15 & 10.2 & $2.42(3)$ & 2.39 & 1.97 & 2.90 & 19.5 & 0.94 & .83 & 1.05 & 11.7 & 2.58 & 2.42 & 2.74 & 6.1 \\
\hline 10 & $7.79(6)$ & 8.30 & 7.10 & 9.49 & 14.4 & $9.05(2)$ & 8.96 & 7.10 & 10.74 & 20.3 & $2.36(3)$ & 2.36 & 1.86 & 2.93 & 22.7 & 1.08 & .87 & 1.28 & 19.0 & 2.54 & 2.33 & 2.76 & 8.4 \\
\hline 11 & $10.93(6)$ & 11.06 & 10.02 & 11.93 & 8.6 & $10.77(6)$ & 10.36 & 9.33 & 11.24 & 9.2 & $2.33(3)$ & 2.34 & 1.91 & 2.83 & 19.7 & 0.97 & .85 & 1.02 & 8.8 & 3.27 & 3.12 & 3.43 & 4.7 \\
\hline 12 & $7.51(6)$ & 7.71 & 6.88 & 8.45 & 10.2 & $7.95(6)$ & 7.70 & 6.90 & 8.50 & 10.4 & $3.12(3)$ & 3.10 & 2.75 & 3.50 & 12.1 & 1.00 & .89 & 1.10 & 10.5 & 2.31 & 2.19 & 2.45 & 5.6 \\
\hline 13 & $5.73(6)$ & 6.01 & 5.18 & 6.79 & 13.4 & $7.01(6)$ & 6.73 & 5.96 & 7.45 & 11.1 & $3.27(3)$ & 3.24 & 2.92 & 3.58 & 10.2 & 1.12 & .98 & 1.26 & 12.5 & 1.86 & 1.73 & 1.99 & 6.9 \\
\hline Mear & 7.90 & 8.21 & 7.22 & 9.11 & 11.7 & 8.29 & 8.02 & 7.04 & 8.98 & 12. & 2.94 & 2.93 & 2.52 & 3.37 & 15.1 & 0.98 & .86 & 1.10 & 12.4 & 2.46 & 2.30 & 2.61 & 6.3 \\
\hline SD & 1.19 & 1.15 & 1.11 & 1.18 & 1.8 & 1.14 & 1.12 & 1.02 & 1.26 & 3. & 0.79 & 0.78 & 0.79 & 0.78 & 4.2 & 0.08 & .06 & 0.10 & 2.6 & 0.36 & 0.35 & 0.37 & 1.0 \\
\hline SEM & 0.33 & 0.32 & 0.31 & 0.33 & 0.5 & 0.34 & 0.34 & 0.31 & 0.38 & 0.9 & 0.22 & 0.22 & 0.22 & 0.22 & 1.2 & 0.02 & .02 & 0.03 & 0.8 & 0.11 & 0.11 & 0.11 & 0.3 \\
\hline
\end{tabular}

$* \dot{\mathrm{V}} \mathrm{CO}_{2}$ data from two infants were eliminated from analysis because of technical difficulties.

$\dagger$ Average measured value of $(n)$ determinations per patient.

$\ddagger$ Best estimate of the true mean value from the linear regression graph (see Fig. 1).

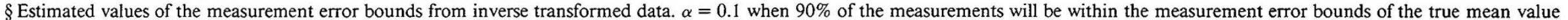
(18).

\| Bandwidth, $\%=[($ upper limit - lower limit $) / 2][100 \%] / \overline{\mathrm{X}}$.

I Estimated from large sample approximations (19). 
consecutive days. The coefficient of variation of $\dot{\mathrm{VO}} \mathrm{O}_{2}$ of the infants they studied was just outside the accuracy $( \pm 4 \%)$ expected during routine measurement of respiratory exchange (29). Furthermore, they claimed that estimation of 24-h energy expenditure from measurements made during $1 \frac{1 / 2-3}{h}$ was valid because the coefficient of variations for measurements performed over $24 \mathrm{~h}$ were low. Other whole-body calorimetry studies confirm this finding $(3,13)$.

According to recent observations $(1,9,12,30,31)$, the respiratory quotient of healthy growing premature infants may be greater than 1.00. When glucose is converted into palmitate, the adipose tissue consumes 27 carbon atoms as glucose to store 16 carbon atoms as palmitate with the remaining 11 carbon atoms appearing as $\mathrm{CO}_{2}$ (32). The ratio of $\mathrm{CO}_{2}$ output to oxygen usage during palmitate synthesis from glucose can be given as:

$$
\begin{aligned}
4.5 \mathrm{C}_{6} \mathrm{H}_{12} \mathrm{O}_{6}+40_{2} \rightarrow & \mathrm{C}_{16} \mathrm{H}_{32} \mathrm{O}_{2}+11 \mathrm{CO}_{2} \\
& +631 \mathrm{kcal} \text { where NPRQ }=11 / 4=2.75 .
\end{aligned}
$$

Consequently, under conditions of lipogenesis, the amount of carbon dioxide excreted through the lungs was greater than oxygen uptake so that the respiratory quotient could rise to values $>1.00(33,34)$. Under these conditions the calculation of metabolic rate using the respiratory gas equations remains valid (17). Of interest was the respiratory quotient data from patient 13 with the highest carbohydrate intake (in the form of rice cereal added to the formula) was associated with the highest respiratory quotient values.

The systems of calorimetry used in the clinical studies were very different which may explain the variable results published on the estimation of resting energy expenditure in the low birth weight neonate. A canopy system or metabolic chamber provides a relatively noninvasive method and allows measurements of gas exchange without the use of a face mask. This avoids discomfort, lessens the chance for air leaks, and avoids facial contact, especially with the trigeminal area which, if stimulated, increases tidal volume, minute ventilation, and the minute ventilation/ $\mathrm{CO}_{2}$ production ratio (35). However, the ventilated hood or face mask system does offer the advantage over the metabolic chamber of shorter response time (about $7 \mathrm{~s}$ for $90 \%$ deflection) and ready access to the infant. Furthermore, a metabolic chamber enclosing the infant limits accessibility, requiring constant supervision of the infant, and careful design of the chamber to minimize access time in case of an emergency. The response time of the metabolic chamber was relatively slow (about $90 \mathrm{~s}$ ) due to the large volume of dead space and gas flow rates and was thus better suited for energy expenditure studies during sleep. It should be kept in mind that the dynamic responsiveness of any combination of flow meter and gas analyzer should be determined and the compensation for lag and delay time must be considered for the accurate analysis of respiratory gas exchange. Although the methods of respiratory gas exchange measurements are highly system specific, they all require meticulous calibration aimed to validate $\mathrm{O}_{2}$ uptake and $\mathrm{CO}_{2}$ production rates of similar magnitude to those encountered in normal calorimetric use (15).

For practical purposes, the clinical factors that contribute appreciably to variation in $\dot{M}$ over the short-term include activity, temperature, and food intake. In these infants in whom sleep accounted for $>90 \%$ of the total measurement time, an increase in physical activity was largely due to changes in the distribution of deep and light sleep. The only practical way of assessing the energy cost of sleep-related physical activity in relation to total $\mathrm{MR}$ was by calorimetry combined with EEG and EOG monitoring. There are relatively few studies, with conflicting data, on premature infants of $\dot{\mathrm{VO}}_{2}$ and $\dot{\mathrm{MR}}$ during sleep (i.e. using indirect calorimetric systems) that employ EEG monitoring allowing for a comparison of heat production during the different sleep states and a comparison of sleep and waking states. Darnall and Ariagno (22) noted no differences in $\dot{\mathrm{VO}}_{2}$ during rapid eye movement and nonrapid eye movement sleep when infants were at thermoneutrality. In contrast, other investigators $(7,21,23,36)$ have reported a $9.4-16.0 \%$ increment in $\mathrm{VO}_{2}$ between quiet and active sleep. No EEG or EOG measurements were made in this study so that the present findings do not permit us to quantitate the energy utilization during sleeprelated physical activity. On the other hand, by using extended experimental periods to incorporate a comparatively wide range of behavioral states we did obtain longitudinal replicate measurements of MR during multiple transitional physiological states.

In summary, during this study, the nutritional and thermal factors known to effect the metabolic rate, were kept constant. Our findings showed that, at least on a short-term basis, the variability in each infants' resting energy expenditure was likely to be largely a result of the variation in individual activity or sleep state. Even though the changes in $\mathrm{VO}_{2}$ during sleep states were relatively small when compared to those that occur with short bursts of maximal muscle contraction, their absolute magnitude was such that they can hardly be considered negligible over time. These and related processes add up to the large energy cost of maintenance. It may be possible that continuous monitoring for sleep state variability (EEG, EOG) and body movements by methods based on electronic imaging or using the Doppler principle (17) could be used to delineate further the variability of energy expenditure in neonates. The number of measurements per infant should be maximized as this directly affects the width of the $90 \%$ confidence interval of the estimated metabolic rate. As expected, the error bounds decrease with increasing number of measurements. Note, for example, the wide confidence interval for patient 10 in whom $\dot{\mathrm{V}} \mathrm{CO}_{2}$, was determined from two samples, compared to the intervals of other patients determined from six samples (Table 2). It was also clear that the investigator must exert considerable judgment in deciding on a minimal level of energy expenditure of infants using indirect calorimetry in the clinical setting. A standardized and rigorous method of testing the apparatus together with the use of the linear regression graph with confidence bands served to ensure that the reported experimental data were accurate as well as providing a quantitative assessment of their uncertainty.

\section{REFERENCES}

1. Chessex P, Reichman BL, Verellen GJE, Putet G, Smith JM, Heim T, Swyer PR 1981 Influence of postnatal age, energy intake, and weight gain on energy metabolism in the very low-birth-weight infant. J Pediatr 99:761-766

2. Whyte RK, Haslam R, Vlainic C, Shannon S, Samulski K, Campbell D, Bayley HS, Sinclair JC 1983 Energy balance and nitrogen balance in growing low birthweight infants fed human milk or formula. Pediatr Res 17:891-898

3. Sauer PJJ, Dane HJ, Visser HKA 1981 Longitudinal studies on metabolic rate, heat loss, and energy cost of growth in low birth weight infants. Pediatr Res 18:254-258

4. Baumgart S 1985 Partitioning of heat losses and gains in premature newborn infants under radiant warmers. Pediatrics 75:89-99

5. Yeh T-F, Admani M. Leu S-T. Tan M, Pildes RS 1982 Simple daily technique to calculate total and interim changes of daily $\mathrm{O}_{2}$ consumption and $\mathrm{CO}_{2}$ production in premature infants. Crit Care Med 10:534-538

6. Brooke OG, Alvear J, Arnold M 1979 Energy retention, energy expenditure and growth in healthy immature infants. Pediatr Res 13:215-220

7. Schulze K, Kairam R, Stefanski M, Sciacca R, Bateman D, Dell R, James LS 1981 Spontancous variability in minute ventilation oxygen consumption and heart rate of low birth weight infants. Pediatr Res 15:1111-1116

8. Schulze K, Kairam R, Stefanski M, Sciacca R, James LS 1981 Continuous measurement of minute ventilation and gaseous metabolism of newborn infants. J Appl Physiol 50:1098-1103

9. Schulze K, Stefanski M, Masterson J, Kashyap S, Sanocka U, Forsyth M Ramakrishnan R, Dell R 1986 An analysis of the variability in estimates of bioenergetic variables in preterm infants. Pediatr Res 20:422-427

10. Abdulrazzaq YM, Brooke OG 1984 Respiratory metabolism in preterm infants: the measurement of oxygen consumption during prolonged periods. Pediatr Res 18:928-931

11. Rutter R, Brown SM, Hull D 1979 Variations in the resting oxygen consumption of small babies. Arch Dis Child 53:850-854

12. Gudinchet F, Schutz Y, Micheli J-L, Stettler E, Jéquier E 1982 Metabolic cost of growth in very low-birth-weight infants. Pediatr Res 16:1025-1030

13. Catzeflis C. Schutz Y. Micheli J-L, Welsch C, Arnaud MJ, Jéquier E 1985 Whole body protein synthesis and energy expenditure in very low birthweight infants. Pediatr Res 19:679-687 
14. Brazelton TB 1973 Clinics in Developmental Medicine No. 50. Neonatal behavioral assessment scale. JB Lippincott Company, Philadelphia, pp 5-8

15. Marks KH. Coen P, Kerrigan JR, Francalancia N, Nardis EE, Sinder MT 1987 The accuracy and precision of an open-circuit system to measure oxygen consumption and carbon dioxide production in neonates. Pediatr Res 21:5865

16. O'Brien D, Ibbott FA, Rodgerson DO 1968 Laboratory manual of pediatric micro-biochemical techniques. Harper and Row Publishers, New York, pp 238-240

17. Jéquier $E 1981$ Long term measurement of energy expenditure in man: direct or indirect calorimetry? In: Björntorp P, Costella M, Howard AN (eds) Recent Advances in Obesity Research, Vol 3. John Libbey, London, pp 130135

18. Kurtz DA. Rosenberger JL, Tamayo GJ 1985 The linear calibration graph and its confidence bands from regression on transformed data. Am Chem Soc 284:133-165

19. Kendall M, Stuart A 1977 The Advanced Theory of Statistics, 4th ed, Vol I. Distribution Theory. Griffin, London

20. Marks KH, Maisels MJ, Moore E, Gifford KG, Friedman Z 1979 Head growth in sick premature infants-a longitudinal study. J Pediatr 94:282-285

21. Stefanski M, Schulze K, Bateman D, Kairam R, Pedley TA, Masterson J, James LS 1984 A scoring system for states of sleep and wakefulness in term and preterm infants. Pediatr Res 18:58-62

22. Darnall RA Jr, Ariagno RL 1982 The effect of sleep state on active thermoregulation in the premature infant. Pediatr Res 16:512-514

23. Dane HJ, Sauer PJJ, Visser HKA 1985 Oxygen consumption and $\mathrm{CO}_{2}$ production of low-birth-weight infants in two sleep states. Biol Neonate 47:205210

24. Bell EF, Rios GR. Wilmoth PK 1986 Estimation of 24-hour energy expenditure from shorter measurement periods in premature infants. Pediatr Res 20:646649

25. Jackson AA, Shaw JCL, Barber A, Golden MHN 1981 Nitrogen metabolism in preterm infants fed human donor breast milk: the possible essentiality of glycine. Pediatr Res 15:1454-1461
26. Shenai JP. Reynolds JW, Babson SG 1980 Nutritional balance studies in verylow-birth-weight infants: enhanced nutrient retention rates by an experimental formula. Pediatrics 66:233-238

27. Fomon SJ, DeMaeyer EM, Owen GM, 1965 Urinary and fecal excretion of endogenous nitrogen by infants and children. J Nutr $85: 235-246$

28. Brooke OG 1985 Energy expenditure in the fetus and neonate: sources of variability. Acta Paediatr Scand [Suppl] 319:128-134

29. Wagner JA, Horvath SM, Dahms TE, Reed S 1973 Validation of open-circuit method for the determination of oxygen consumption. J Appl Physiol 34:859-863

30. Okken A 1979 Nutrition and Metabolism of the Fetus and Infant. In: Visser HKA (ed) Fifth Nutricia Symposium. Martinus Nijhoff Publishers, The Hague, pp 158-165

31. Sauer PJJ, Pearse RG, Dane HJ, Visser HKA 1979 The energy cost of growth estimated from simultaneous direct and indirect calorimetry in infants less than 2500 g. In: Visser HKA (ed) Fifth Nutricia Symposium. Nutrition and Metabolism of the Fetus and Infant. The Hague, Martinus Nijhoff Publishers, pp 93-107, 161

32. McGilvery RW, Goldstein GW 1983 Biochemistry: A Functional Approach. WB Saunders, Philadelphia, pp 545-546

33. Frayn KN 1983 Calculation of substrate oxidation rates in vivo from gaseous exchange. J Appl Physiol 55:628-634

34. Acheson KJ, Schutz Y, Bessard T, Ravussin E, Jéquier E, Flatt JP 1984 Nutritional influences on lipogenesis and thermogenesis after a carbohydrate meal. Am J Physiol 246(Endocrinol Metab 9):E62-E70

35. Askanazi J, Silverberg PA, Foster RJ, Hyman AI, Milic-Emili J, Kinney JM 1980 Effects of respiratory apparatus on breathing pattern. J Appl Physio 48:577-580

36. Kairam R, Schulze K, Koenigsberger M, James LS 1979 The effects of changing sleep state on autonomic functions in the newborn. Pediatr Res 13:498 (abstr)

37. Lubchenco LO, Hansman C, Dressler M, Boyd E 1963 Intrauterine growth as estimated from liveborn birth-weight data at 24 to 42 weeks of gestation. Pediatrics 32:793-800 